\title{
Where have all the diseases gone during the COVID-19 pandemic?
}

\author{
Anirudh Kohli, Aditya Shetty, Anagha Joshi' ${ }^{1}$, Ashank Bansal ${ }^{1}$ \\ Department of Radiology, Breach Candy Hospital and Trust, 'Department of Radiology, Lokmanya Tilak Municipal Medical \\ College and Hospital, Mumbai, Maharashtra, India
}

Correspondence: Dr. Aditya Shetty, 83/B, Warden Road, Sophia College Lane, Mumbai, Maharashtra, India. E-mail: adityashetty01@gmail.com

\begin{abstract}
This article focuses on a marked drop in volumes in the lockdown period during the COVID-19 pandemic across all modalities X-ray, sonography, CT scan and MRI scans and compares the volumes of data between a private and public hospital in Mumbai. This trend has been witnessed globally also. Even with easing of lockdown this has not reflected in an increase in numbers. Imaging volumes of a 1900-bed public hospital and a 220-bed private hospital in Mumbai were collated for all modalities, i.e., X-ray, sonography, CT and MRI for the months January, February 2020- Prelockdown, March 2020 Peri-lockdown, April, May 2020- Lockdown, June Unlock 1.0, July Unlock 2.0. The imaging volumes during lockdown, Unlock, were compared with prelockdown values. It was initially felt that this was due to a fear of visiting hospitals that are considered hotbeds of SARS-CoV-2. However, the same status has persisted over the 2 months of lockdown and the 2 months of unlocking. What is the cause of this huge drop in imaging volumes?
\end{abstract}

Key words: Covid -19 pandemic; lockdown; Mumbai hospitals; non-COVID; prelockdown; unlock

\section{Introduction}

Do we prepare for a surge of non-COVID diseases postpandemic?

The key to controlling the COVID-19 pandemic is social distancing, mask and sanitization. This has been publicly advocated through every possible medium. In Mumbai, every billboard was acquired by the municipal corporation from early March with educational messages regarding COVID 19. Every mobile call is preceded by an educational message about COVID-19. In view of this extensive education on social distancing as well as outbreaks of COVID-19 in healthcare establishments, patients are distancing themselves from healthcare establishments. In addition, healthcare establishments were encouraging

\begin{tabular}{|c|c|}
\hline \multicolumn{2}{|c|}{ Access this article online } \\
\hline Quick Response Code: & \\
\hline \multirow{2}{*}{ 口仿要 } & $\begin{array}{l}\text { Website: } \\
\text { www.ijri.org }\end{array}$ \\
\hline & $\begin{array}{l}\text { DOI: } \\
\text { 10.4103/ijri.IJRI_721_20 }\end{array}$ \\
\hline
\end{tabular}

only essential/emergency examinations in the early part of lockdown. A study was undertaken to evaluate the impact on imaging volumes at a prominent public and private hospital in Mumbai. Essentially two ends of the economic spectrum to avoid any bias.

\section{Materials and Methods}

Imaging volumes of a 1900 bed public hospital and a 220-bed private hospital in Mumbai were collated for all modalities, i.e., X-ray, sonography, CT and MRI for the months January, February 2020- Prelockdown, March 2020 Peri-lockdown, April, May 2020- Lockdown, June Unlock

This is an open access journal, and articles are distributed under the terms of the Creative Commons Attribution-NonCommercial-ShareAlike 4.0 License, which allows others to remix, tweak, and build upon the work non-commercially, as long as appropriate credit is given and the new creations are licensed under the identical terms.

For reprints contact: WKHLRPMedknow_reprints@wolterskluwer.com

Cite this article as: Kohli A, Shetty A, Joshi A, Bansal A. Where have all the diseases gone during the COVID-19 pandemic? Indian J Radiol Imaging 2021;31:S119-21.

Received: 10-Sep-2020 Revised: 22-Oct-2020

Accepted: 27-Dec-2020 Published: 23-Jan-2021 
Kohli, et al:: Where have all the diseases gone during the COVID-19 pandemic?

Table 1: Comparison of volume of each modality during prelockdown, lockdown and unlock

\begin{tabular}{|c|c|c|c|c|c|c|c|c|}
\hline & \multicolumn{2}{|c|}{ X-ray } & \multicolumn{2}{|c|}{ USG } & \multicolumn{2}{|c|}{ CT } & \multicolumn{2}{|c|}{ IMRI } \\
\hline & Public & Private & Public & Private & Public & Private & Public & Private \\
\hline Pre-lockdown & 14575 & 4019 & 6379 & 1422 & 2904 & 852 & 628 & 822 \\
\hline Lockdown & 6722 & 1087 & 2243 & 315 & 789 & 185 & 59 & 93 \\
\hline Unlock & 7986 & 2065 & 2823 & 306 & 1125 & 433 & 148 & 170 \\
\hline
\end{tabular}

Table 2: Percentage of volume during lockdown and unlock as compared to prelockdown

\begin{tabular}{|c|c|c|c|c|c|c|c|c|}
\hline & \multicolumn{2}{|c|}{ X-Ray } & \multicolumn{2}{|c|}{ USG } & \multicolumn{2}{|c|}{ CT } & \multicolumn{2}{|c|}{ MRI } \\
\hline & Public & Private & Public & Private & Public & Private & Public & Private \\
\hline Pre-lockdown & 100 & 100 & 100 & 100 & 100 & 100 & 100 & 100 \\
\hline Lockdown & 46 & 27 & 35 & 22 & 27 & 22 & 9 & 11 \\
\hline Unlock & 55 & 52 & 44 & 22 & 39 & 51 & 24 & 21 \\
\hline
\end{tabular}

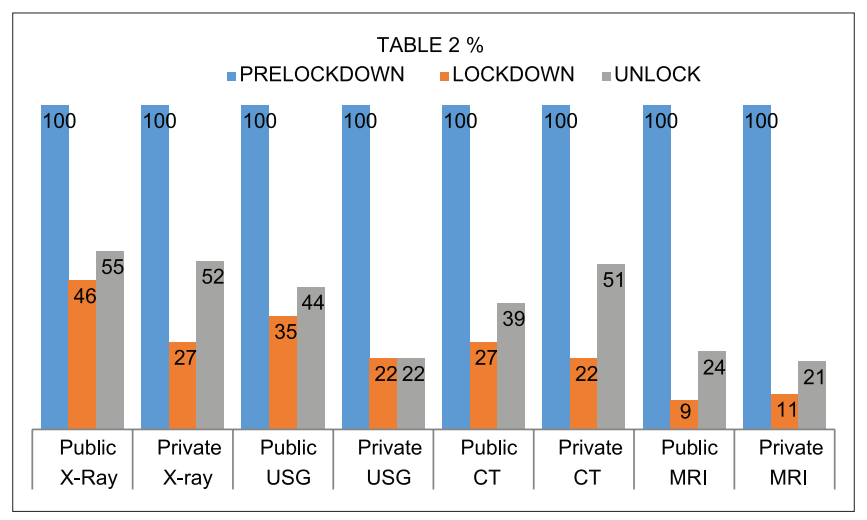

1.0, July Unlock 2.0. The imaging volumes during lockdown, Unlock, were compared with prelockdown values.

In addition, volumes for emergency investigations, stroke - CT/MRI, Acute fractures - X-Ray, Acute abdomen $\mathrm{X}$-ray/sonography/CT/MRI were collated during pre lockdown, lockdown unlock $1.0 / 2.0$ periods and compared with prelockdown values.

\section{Results}

Chi-square test analysis was performed and proved to be significant with a value $P<0.05$.

Tables 1-3 reveal that imaging volume of each modality like X-ray, USG, CT scan, and MRI had significantly dropped during lockdown in both Public and Private Hospitals as compared to pre lockdown. Drop is ranging from 50.0 to $90.0 \%$.

During the unlocked period imaging volume has started increasing trend in all the modalities but will take some more periods to reach to pre lockdown numbers.

\section{Discussion}

In the lockdown period there has been a marked drop in volumes, even with easing of lockdown this has not reflected in an increase in numbers. This drop has been seen across all modalities. X-ray and CT scan especially in a private setting showed some recovery as they were being used mainly for COVID pneumonia evaluation.

This trend has been witnessed globally also..$^{[1-3]}$

It was initially felt that this was due to a fear of visiting hospitals that are considered hotbeds of SARS-CoV-2. However, the same status has persisted over the two months of lockdown and the two months of unlocking.

What is the cause for this huge drop in imaging volumes?

At first, it was considered that all non-emergent and non-essential imaging was being postponed by patients, clinicians, and healthcare facilities. However, drops of $80-90 \%$ cannot be explained only on this basis.

This prompted a study of emergency imaging, X-rays for fractures, CT/MRI for stroke, X-ray/sonography/ CT/MRI for acute abdomen. This covers broadly the emergency spectrum across organs and modalities. All these emergency investigations also showed a significant drop as compared to pre-lockdown. This naturally sparked off a debate where have all the disease or patients gone? 
Table 3: Percentage of emergency investigations for stroke, acute fracture and acute abdomen

\begin{tabular}{lcccccccc}
\hline & \multicolumn{2}{c}{ Acute fracture } & & \multicolumn{2}{c}{ Acute abdomen } & & \multicolumn{2}{c}{ Strokes } \\
\cline { 2 - 3 } & Public & Private & & Public & Private & & Public & Private \\
\hline Pre-lockdown & 100 & 100 & & 100 & 100 & & 100 & 100 \\
Lockdown & 25 & 36 & & 45 & 33 & & 49 & 22 \\
Unlock & 34 & 31 & & 28 & 27 & & 65 & 25
\end{tabular}

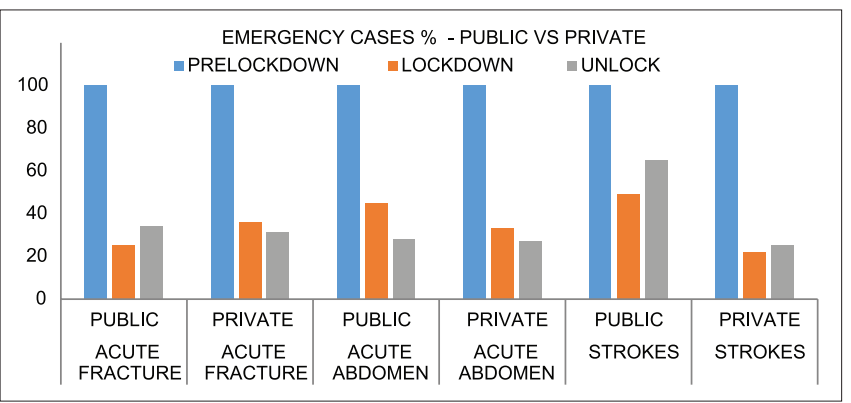

1 Is it that patients are at home with less stress, home food, leading healthier lifestyles, so there are less strokes, less myocardial infarcts?

2 Is it due to the suspension of inter-district and inter-state travel? As many patients from the periphery drain into metropolis; however, travel for medical reasons was freely permitted.

3 Is it because there are no engines to bring diseases into the forefront. Preventive medicine in the form of Health check programs and doctors' clinics are not open to screen patients to detect silent diseases.

4 Or are patients sitting on a ticking time bombs as they delay diseases that will progress and they will present with advanced disease, likely oncological disease. This is unfortunate as early detection has proven to reduce the mortality and morbidity in especially oncological diseases.

\section{Conclusion}

It seems that all this may be a combination of all the four thought processes.

The main shocker is the reduction in disease process requiring emergency imaging, admission and therapy. These findings are definitely going to stimulate activists against health check, screening programs, those in favour of holistic lifestyles to point out the industry medicine has become. However, the role of the health check screening programs have been proven beyond doubt. Hopefully, individuals will find the perfect balance of a healthier lifestyle, less stress, judicious utilisation of preventive and therapeutic healthcare.

Financial support and sponsorship

Nil.

\section{Conflicts of interest}

There are no conflicts of interest.

\section{References}

1. Boeken T, Le Berre A, Mebazaa A, Boulay-Coletta I, Hodel J, Zins M. Non-COVID-19 emergencies: Where have all the patients gone? Eur Radiol 2020;30:5220-1.

2. Naidich JJ, Boltyenkov A, Wang JJ, Chusid J, Hughes D, Sanelli PC. Impact of the Coronavirus disease 2019 (COVID-19) pandemic on imaging case volumes. J Am Coll Radiol 2020;17:865-72.

3. Cavallo JJ, Forman HP. The economic impact of the COVID-19 pandemic on radiology practices. Radiology 2020;296. https://doi. org/10.1148/radiol.2020201495.

\section{Comparison of Imaging Volume of Each Modality During Pre Lockdown, Lockdown and Unlock}

Comparison of imaging volume of each modality during pre-lockdown, lockdown and unlock

\begin{tabular}{|c|c|c|c|c|c|c|}
\hline \multirow[t]{2}{*}{ Test } & \multicolumn{2}{|c|}{ Pre Lockdown } & \multicolumn{2}{|c|}{ Lockdown } & \multicolumn{2}{|c|}{ Unlock } \\
\hline & Public No. (\%) & Private No. (\%) & Public No. (\%) & Private No. (\%) & Public No. (\%) & Private No. (\%) \\
\hline X-ray & $14575(100.0)$ & $4019(100.0)$ & *6722 (46.1) & *1087 (27.0) & $7986(54.8)$ & $2065(51.4)$ \\
\hline USG & $06379(100.0)$ & $1422(100.0)$ & *2243 (35.2) & ${ }^{*} 0315(22.1)$ & $2823(44.3)$ & $0306(21.5)$ \\
\hline СТ & $02904(100.0)$ & $0852(100.0)$ & ${ }^{*} 0789(27.2)$ & *0185 (21.7) & $1125(38.7)$ & 0433 (50.8) \\
\hline MRI & $00628(100.0)$ & $0822(100.0)$ & *0059 (09.4) & ${ }^{*} 0093(11.3)$ & $0148(23.6)$ & $0170(20.7)$ \\
\hline
\end{tabular}

By Chi-square test; *Significant, $P<0.05$.

These data reveal that imaging volume of each modality like x-ray, USG, CT scan and MRI had significantly dropped during lockdown in both Public and Private Hospitals as compared to pre lockdown. The drop was ranging from 50. 0 to $90.0 \%$.

During unlock period imaging volume has started an increasing trend in all the modalities but will take some more periods to reach to pre lockdown numbers. 